\title{
Valproic Acid: One Drug, One Patient, and Multiple Reactions
}

\author{
Indar Kumar Sharawat ${ }^{1,} \quad$ Ananthanarayanan Kasinathan ${ }^{2} \quad$ Lesa Dawman ${ }^{3}$
}

\author{
${ }^{1}$ Department of Pediatrics, Pediatric Neurology Division, \\ All India Institute of Medical Sciences, Rishikesh, India \\ 2Department of Pediatrics, JIPMER, Pondicherry, India \\ ${ }^{3}$ Department of Pediatrics, Postgraduate Institute of Medical \\ Education and Research, Chandigarh, India
}

J Neurosci Rural Pract:2020;11:509-510

A 16-year-old adolescent girl living with juvenile myoclonic epilepsy sought medication for tremulous hands and declining handwriting skills for the last 2 months. Her epilepsy was under remission for the past 1 year with sodium valproate monotherapy $(1,000 \mathrm{mg} /$ day $)$. The drop in her writing abilities was secondary to tremulous hands when outstretched or under action. The tremulousness was restricted to the hands; spared other body parts and it abated with sleep. There was no cognitive decline, motor deficit, speech, and gait abnormality of note. Anthropometry revealed a body mass index of 30.1 (height: $155.4 \mathrm{~cm}$; weight: $72.8 \mathrm{~kg}$ ) and her mother-tendered concerns of excessive weight gain $(10 \mathrm{~kg})$ in the past 4 months. Her previously consistent menstrual cycles became irregular from the age of 15 , and she has not menstruated for the past 4 months. Signs of alopecia, hirsutism, and neck swelling were unremarkable. Neurological examination revealed 4 to $6 \mathrm{~Hz}$ postural tremors of bilateral hands.

Baseline investigations showed normal hemogram, liver function tests, bone profile, and euglycemia. Her serum ammonia and valproate drug estimations $(92 \mathrm{mg} / \mathrm{L}$ ) were appropriate. Hormonal assay identified elevations in thyroid-stimulating hormone (TSH) $(18.4 \mathrm{mU} / \mathrm{L})$ and luteinizing hormone level. Free T3 and T4 levels; prolactin, lipid profile, follicle stimulating hormone, and free and total testosterone levels were unremarkable (-Table $\mathbf{1}$ ). Ultrasound abdomen exhibited multiple small cysts in bilateral ovaries (-Fig. 1). The possibility of sodium valproate induced adverse reaction was considered with a Naranjo adverse drug reaction probability score of 4 . VPA was stopped and she was started on levetiracetam monotherapy. After 1 month, there was complete resolution of the action-postural tremors with a remarkable change in her lettering. At 3-month follow-up, she had lost $6 \mathrm{~kg}$ of weight; her menstruation cycle had resumed and her thyroid-stimulating hormone levels became normal $(4.9 \mathrm{mU} / \mathrm{L})$.

The adverse effect profile of our index child is distinctive for the myriad of symptoms that could have been prevented with early recognition and proper monitoring
Address for correspondence Indar Kumar Sharawat, DM, Department of Pediatrics, Pediatric Neurology Division, All India Institute of Medical Sciences, Rishikesh 249203, India (e-mail: sherawatdrindar@gmail.com).

Table 1 Endocrine profile of the patient

\begin{tabular}{|l|l|l|}
\hline Parameters & Value & $\begin{array}{l}\text { Reference } \\
\text { range }\end{array}$ \\
\hline Thyroid stimulating hormone $(\mathrm{mU} / \mathrm{L})$ & 18.4 & 4.8 \\
\hline Free T3 $(\mathrm{ng} / \mathrm{dL})$ & 187.3 & $80-200$ \\
\hline Free T4 $(\mathrm{ng} / \mathrm{dL})$ & 7.9 & $5.1-14.1$ \\
\hline Parathyroid hormone $(\mathrm{pg} / \mathrm{mL})$ & 32.6 & $10-65$ \\
\hline Prolactin $(\mathrm{ng} / \mathrm{mL})$ & 14.6 & $2-35$ \\
\hline Adrenocorticotropic hormone $(\mathrm{pg} / \mathrm{mL})$ & 28.2 & $10-60$ \\
\hline Cortisol $(\mathrm{mcg} / \mathrm{dL})$ & 12.6 & $10-22$ \\
\hline Insulin $(\mathrm{mlU} / \mathrm{L})$ & 88 & $16-200$ \\
\hline Follicle stimulating hormone $(\mathrm{mlU} / \mathrm{mL})$ & 4.9 & $0.8-10$ \\
\hline Luteinizing hormone $(\mathrm{mlU} / \mathrm{mL})$ & 13.2 & $1.8-12.6$ \\
\hline Free testosterone $(\mathrm{pg} / \mathrm{mL})$ & 1.6 & Less than 7 \\
\hline Total testosterone $(\mathrm{ng} / \mathrm{dL})$ & 32.6 & $9-88$ \\
\hline
\end{tabular}

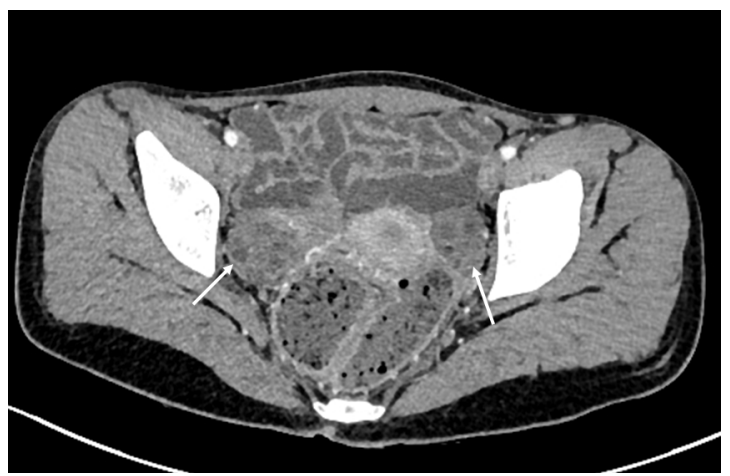

Fig. 1 Computerized tomography scan of the pelvis. Axial section showed multiple small cysts in bilateral ovaries (arrow).

during follow-up visits over 2 years. Neurological adverse events including dizziness, memory deficits, insomnia and in our case, tremors were the most common adverse effects responsible for VPA monotherapy discontinuation in a randomized controlled trial of childhood absence epilepsy. 
Approximately 10 to $25 \%$ of patients on valproate therapy develop tremors that are predominantly action or postural in nature. ${ }^{1}$ Potentiation of GABAergic neurotransmission by reversible inhibition of enzyme GABA transaminase with subsequent reduction of high-frequency neuronal firing is the postulated mechanism. The metabolic adverse events such as weight gain, high body mass index, hypertriglyceridemia, and reduced high-density lipoprotein levels have been described in VPA-treated patients when compared with healthy controls. ${ }^{2}$ A positive relationship between the increase in weight and length of treatment ( $>3$ months) has been reported by Grosso et al. ${ }^{3}$ In addition, the problem is compounded by VPA-induced endocrine adverse events such as leptin resistance, hyperinsulinemia, and hyperleptinemia that augment additional weight gain. The etiology of weight gain in the index patient is theorized to be multifactorial in origin: chronic VPA therapy, subclinical hypothyroidism, and polycystic ovarian disease have a part to play. The occurrence of weight gain from VPA is not dose-dependent and defies prediction. Given the high efficacy of valproate in juvenile myoclonic epilepsy and the inherent risk of weight gain with chronic therapy, a change in prescription to the extendedrelease preparation of VPA has been found to be beneficial. The problem is circumvented by "start low go slow" principle of up to $1,000 \mathrm{mg}$ of extended-release valproate monotherapy; beyond which alternate options to be considered. The subclinical hypothyroidism in our girl is consistent with current literature that states a very high incidence of around $50 \%$ in children with chronic VPA therapy. ${ }^{4}$ Subclinical hypothyroidism, signifying the early stage of thyroid dysfunction, has been found to be prevalent among long-term (median of 21 months) treated children by Sahu et al. ${ }^{5}$ An independent study by Vainionpaa et $\mathrm{al}^{6}$ demonstrated subclinical hypothyroidism in girls 8 to 18 years of age even after valproate withdrawal. The exact mechanism of thyroid dysfunction by VPA is unclear; secondary zinc/selenium deficiency and somatostatin inhibition by VPA are still conjectural. Another dreaded complication of chronic VPA therapy that acts as an independent risk factor for metabolic disturbances such as insulin resistance and dyslipidemia is polycystic ovarian syndrome (PCOS). A recent meta-analysis by $\mathrm{Hu}$ et $\mathrm{al}^{7}$ identified a 1.9-fold increased risk of PCOS with VPA when compared with other seizure medication in women. No significant dose or duration related increased frequency of PCOS has been identified in women highlighting the need for future prospective studies. Our case emphasizes the need for early recognition of drug-related side effects and also closes monitoring of children especially girls on chronic VPA monotherapy.

\section{Funding}

None.

\section{Conflict of Interest}

None declared.

\section{References}

1 Morgan JC, Sethi KD. Drug-induced tremors. Lancet Neurol 2005;4(12):866-876

2 Mania M, Kasradze S, Okujava N. Valproic acid related metabolic syndrome in patients with epilepsy. Georgian Med News 2011;(194):43-47

3 Grosso S, Mostardini R, Piccini B, Balestri P. Body mass index and serum lipid changes during treatment with valproic acid in children with epilepsy. Ann Pharmacother 2009;43(1):45-50

$4 \mathrm{Kim} \mathrm{SH}$, Chung HR, Kim SH, et al. Subclinical hypothyroidism during valproic acid therapy in children and adolescents with epilepsy. Neuropediatrics 2012;43(3):135-139

5 Sahu JK, Gulati S, Kabra M, Arya R, Sharma R, Gupta N, et al. Evaluation of subclinical hypothyroidism in ambulatory children with controlled epilepsy on valproate monotherapy. J Child Neurol 2012;27:594-597

6 Vainionpää LK, Mikkonen K, Rättyä J, Knip M, Pakarinen AJ, Myllylä VV, et al. Thyroid function in girls with epilepsy with carbamazepine, oxcarbazepine, or valproate monotherapy and after withdrawal of medication. Epilepsia 2004;45:197-203

7 Hu X, Wang J, Dong W, Fang Q, Hu L, Liu C. A meta-analysis of polycystic ovary syndrome in women taking valproate for epilepsy. Epilepsy Res 2011;97(1-2):73-82 